\title{
Mathematical Modeling of Heat and Mass Transfer in Heat Pipes in a One-Dimensional Formulation when Cooling Active Phased Antenna Arrays
}

\author{
S. Radaev \\ Moscow Aviation Institute (National Research University) \\ Moscow, Volokolamskoe shosse 4, 125993, \\ Russian Federation
}

Received: February 16, 2021. Revised: August 7, 2021. Accepted: September 9, 2021. Published: September 10, 2021.

\begin{abstract}
The work proposes test one-dimensional models of heat and mass transfer in heat pipes during cooling of active phased antenna arrays, which can be used in processing the test results of flat heat pipes in order to determine their performance characteristics and identify the parameters required for modeling in a more complex setting (for example, in flat and taking into account the presence of several localized sources of heat supply).

To take into account the influence of the heat release power on the equilibrium temperature inside the heat pipe, the model has been added to take into account the dependence of the steam saturation temperature on the pressure, which is realized inside the steam pipeline when the heat pipe is heated.

Numerous calculations carried out made it possible to refine the mathematical model. In particular, a significant effect on the temperature distribution along the heat pipe is shown, taking into account the dependence of the steam saturation temperature on the pressure in the parawire.

It is shown that the introduction of standard functions for the characteristics of the coolant (water) in the liquid and vapor state, as well as taking into account the capillary pressure on temperature, makes it possible to refine the resulting solution.
\end{abstract}

Keywords-Heat pipes, active phased antenna arrays, operational characteristics, heat and mass transfer, mathematical modeling.

\section{INTRODUCTION}

$C$ URREnTLY, active phased antenna arrays are widely

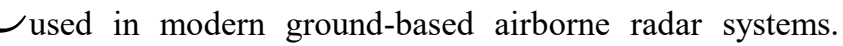
They are used by the active aperture method, in particular to generate very high power, which can be satisfied with active phased systems. The main parameters of modern radar systems are mainly due to the performance of the transmit/receive amplifier modules used in the system. Receiving/transmitting devices, which are located on the antenna web in each radiator and emit a large amount of thermal energy.

Cooling of active phased antenna arrays at a high heat flux density is especially important when moving to a higher frequency range, when the dimensions of the element base and, accordingly, modules decrease, and the heat release practically does not change [1]-[9]. An increase in the efficiency of heat removal can be achieved, in particular, with the help of liquid cooling systems in a strictly limited volume for their placement, which is the most important condition for the creation of modern antennas. Therefore, today the use of flat heat pipes is the most relevant. However, it is necessary to take into account the distribution of heat power, the intensity of local heat fluxes of heat-loaded elements and the small size of the gap between the modules [10]-[26].

For mathematical modeling of heat and mass transfer in heat pipes, we will use the model of flat heat pipes proposed in [27]-[30] and used in works [31]-[53] in various complicated and modified versions. A similar model was also used in works [54]-[82]. This model is, in fact, a generalization of the onedimensional setting for the two-dimensional case.

In such conditions, it can be assumed that one-dimensional heat and mass transfer processes are implemented inside the 
heat-dissipating base, the modeling of which is carried out in this section of the report.

Earlier, a model was developed to describe the processes of heat and mass transfer in the products under consideration. This model, in particular, was used in the published work [40], where optimization of the geometry of heat pipes was carried out.

To take into account the effect of the heat release power on the equilibrium temperature inside the heat pipe, the mathematical model has been added to take into account the dependence of the steam saturation temperature on the pressure, which is realized inside the steam pipeline when the pipe is heated.

To implement this modification, the model of the steam flow in the parawire was supplemented with a time dependence, which allows you to set the necessary initial conditions (vacuum pressure in the heat pipe, set during the manufacturing process) and determine the pressure and the corresponding saturation temperature of steam in the steady state.

\section{STATEMENT OF THE TASK}

A variant of flat heat pipes of length $a$, width $b$ and thickness $H$ is considered, and $H \ll a, b$, which is the basis for the transition, at the beginning to a flat formulation of the problem, and then to a one-dimensional one under specially selected simplified test conditions. In particular, the following experimental scheme is considered: at one end of the base there is a heat source having a width $b$ and a length $a_{l}$, at the other end there is a condensation zone, which also has a width $b$ and a length $a_{2}$, and $a_{1}, a_{2}<<a$. The schematic of this experiment is shown in Figure 1. The length of the condensation zone $a_{2}$, the evaporation zone $a_{1}$, and the adiabatic section $a$. The angle of inclination to the horizon $\theta$. In such conditions, it can be assumed that one-dimensional heat and mass transfer processes are implemented inside the heat-dissipating base, the modeling of which is carried out in this section of the report.

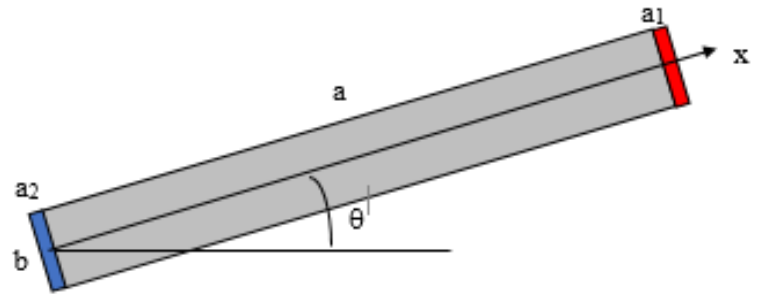

Fig. 1 An example of a simplified heat pipe diagram allowing the use of a one-dimensional setting.

Earlier, a model was developed to describe the processes of heat and mass transfer in the products under consideration. This model, in particular, was used in the published work [40], where optimization of the geometry of heat pipes was carried out. Within the framework of a one-dimensional problem and stationary processes, the model is written as follows. The problem of thermal conductivity in the wall of the body of the heat sink base, on which the source is installed, has the form:

$$
\begin{gathered}
k_{s} H_{s} \frac{d^{2} T}{d x^{2}}=h_{p}\left(T-T_{s a t}\right)+h_{0}\left(T-T_{0}\right) ; \\
x=0: T=T_{0} ; \\
x=a: q=\phi .
\end{gathered}
$$

where $T(x)$ - case wall temperature, $k_{s}-$ thermal conductivity coefficient of the housing wall material, $H_{s}-$ wall thickness, $\phi$ - input heat flux in the evaporator zone, $h_{p}=k_{l} / H_{l}$ - coefficient of heat transfer from the wall of the base body to the internal space (steam line), which is determined by the ratio of the coefficient of thermal conductivity of the wick layer saturated with liquid, $k_{l}$ to its thickness $H_{l} ; h 0$ coefficient of heat transfer from the wall surface to the external environment, which under conditions of free convection at normal ambient temperature $T_{0}=25^{\circ} \mathrm{C}$, taken equal 5 $\mathrm{W} /\left(\mathrm{m}^{2} \mathrm{~K}\right) ; T_{\text {sat }}\left(P_{\text {sat }}\right)$ - temperature of saturated steam in the steam line, depending on the given saturation pressure (selected during manufacture), $q=-k_{s} d T / d x-$ is the heat flux in the wall of the case.

In the evaporator zone, the supplied heat flux is calculated taking into account the power of the source $P$ (we neglect the losses from the source surfaces, which goes into reserve when evaluating the temperature of its heating):

$$
\phi=\frac{P}{b H_{s}}
$$

Outside the evaporation/condensation zone, it is assumed that heat losses to the surrounding space can be neglected and the processes taking place inside the heat sink base can be considered adiabatic. It is also assumed that the temperature in the condensation zone is kept constant using intensive air or liquid cooling.

Filtration parameters of a liquid in a porous wick are estimated using the Darcy model:

$$
\begin{aligned}
& \rho_{l} H_{l} \frac{d u_{l}}{d x}=-\alpha ; \\
& x=0, a: u_{l}=0 .
\end{aligned}
$$

where $u_{l}=-\left(K / \mu_{l}\right) d P_{l} / d x$ - fluid filtration rate, $P_{l}$ - fluid pressure, $\alpha=h_{p}\left(T-T_{s a t}\right) / L_{v}$ - the rate of evaporation of the liquid, calculated as the ratio of the supplied heat flux to the heat of vaporization $L_{v}$.

The total pressure in the fluid is calculated taking into account the gravitational forces: 


$$
P_{l}^{*}=P_{l}+\rho_{1} g(a-x) \sin \theta .
$$

With a horizontal arrangement of the heat-removing base $(\theta$ $=0)$ the influence of gravitational forces is neglected, but with an increase in the angle of inclination $(\theta>0)$, at which the evaporation zone is above the condensation zone, the contribution of gravity is approximately taken into account as the pressure of a liquid column located above a given point assuming that the wick is completely saturated with liquid along its entire length.

The parameters of heat and mass transfer in a steam pipeline are calculated on the assumption of a laminar flow based on the following relations, which are valid for a gas flow between two flat walls:

$$
\begin{aligned}
& \rho_{v} H_{v} \frac{d u_{v}}{d x}=-\alpha \\
& x=0, a: u_{v}=0
\end{aligned}
$$

where $u_{v}=-\left(12 H_{v}^{2} / \mu_{v}\right) d P_{v} / d x-$ gas flow rate, $P_{v}-$ gas pressure, $H_{v}$ - height of the steam line area (distance between the walls of the heat sink base), $\rho_{v}, \mu_{v}$ - gas density and viscosity.

Thus, the related problem of heat and mass transfer is solved and the temperature on the wall of the heat pipe body, the pressure and velocity of the liquid in the wick and vapor in the parawire are determined. A one-dimensional process of heat propagation in the wall of a heat sink base is simulated based on the solution of problem (1), (2), which takes into account heat exchange with the heat carrier inside the steam pipeline and with the external environment. The vapor pressure in the steam line and the liquid in the wick are found from solving the problems of mass transfer (3), (4), which take into account the processes of condensation/evaporation, which depend on the thermal state of the wall. Note that problems (3), (4) are boundary value problems with boundary conditions of the Neumann type and therefore their solutions are determined up to a constant. This constant is determined from the additional condition that in the steady-state mode of operation, the average pressure in the coolant is equal to the initial vacuum pressure $\left(P_{\text {sat }}\right)$, which is created inside the tube during manufacture.

From the solution of the problem of thermal conductivity, the temperature in the evaporator zone is determined, which is measured in the experiment. Based on the solution of the problems of mass transfer, the margin is determined according to the capillary limit of the heat-removing base, taking into account the following relation:

$$
\Delta P_{c}>\Delta P_{l}^{*}+\Delta P_{v}
$$

where $\Delta P_{c}=2 \sigma / r_{e f f}-$ wick capillary pressure, $\Delta P^{*}{ }_{l}$, $\Delta P_{v}$ - pressure drop in liquid and steam, respectively, $\sigma$ surface tension, $r_{e f f}-$ wick characteristic pore size.

The value $\Delta P_{c} /\left(\Delta P_{l}^{*}+\Delta P_{v}\right)$ determines the "margin" according to the capillary limit of the tube operability at a given heat supply power. When the capillary limit $\left(\Delta P_{c} /\left(\Delta P_{l}^{*}+\Delta P_{v}\right)=1\right)$ is reached, the pressure drop becomes too large and the liquid cannot be returned to the evaporation zone due to capillary forces. This limit determines the maximum heat generation that the heat pipe can transmit during normal operation (without overheating, "drying out" of the wick in the evaporation zone, etc.).

\section{CAlCUlation RESUltS}

The calculations were carried out using a one-dimensional formulation of the model of heat and mass transfer in a flat heat pipe.

Figure 2 shows the results of mathematical modeling. From the presented results, it can be seen that heating and heat transfer in a cooled base in the form of a heat pipe has a fundamentally different character than in a solid material. In the heat pipe, an equilibrium temperature is established practically along the entire length, and a sharp temperature change is realized near the zone of heat supply/removal.

The following important errors of the model can be noted. First, the fixed value of the saturation temperature inside the heat pipes leads to a constant value of the temperature of its surface, which does not correspond to the experimental data. Secondly, the overestimated values of the predicted temperature in the area of the location of heat sources. Thirdly, this is the presence of a zone of linear temperature change at the cold end of the heat pipe - in the calculations in this zone, after the equilibrium temperature value close to the saturation temperature, a nonlinear (exponential) segment of temperature change is realized.

To take into account the effect of the heat release power on the equilibrium temperature inside the heat pipe, the mathematical model has been added to take into account the dependence of the steam saturation temperature on the pressure, which is realized inside the steam pipeline when the pipe is heated.

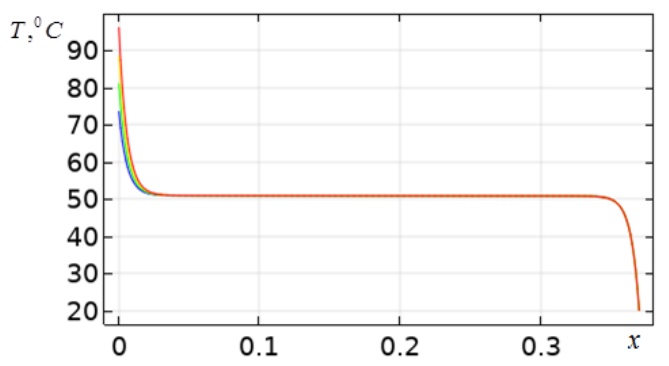

Fig. 2 Distribution of temperature along the length of the heat pipe. The colors indicate the heat dissipation power at the sources: blue - $30 \mathrm{~W}$, green $-40 \mathrm{~W}$, orange $-50 \mathrm{~W}$, red $-60 \mathrm{~W}$. 
To implement this modification, the model of the steam flow in the parawire was supplemented with a time dependence, which allows you to set the necessary initial conditions (vacuum pressure in the heat pipe, set during the manufacturing process) and determine the pressure and the corresponding saturation temperature of steam in the steady state.

The dependence of the saturated steam temperature on the pressure $T_{\text {sat }}\left(P_{v}\right)$ was taken from the reference data for the selected type of coolant (bidistillate), and is shown in Fig. 3.

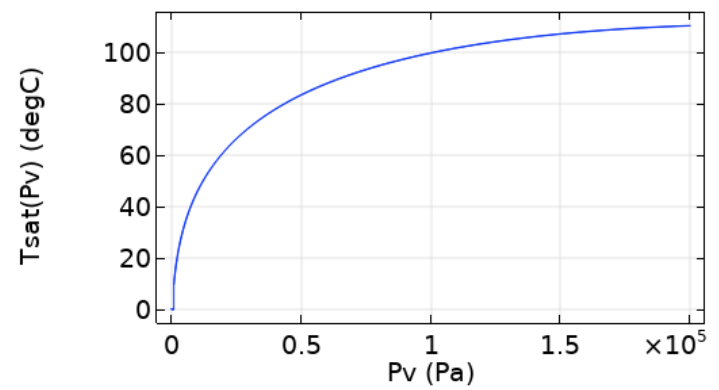

Fig. 3 Dependence of the saturation temperature on the pressure for the coolant (bidistillate), specified in the calculations.

The calculation results obtained with the addition of the specified refinement are shown in Fig. 4. It can be seen here that the equilibrium temperature of the TT surface turns out to depend on the specified heat release power (vertical displacement of the horizontal section of the graphs). This effect is in qualitative agreement with experimental data. As can be seen from Fig. 4 in the area where the sources are located, a temperature increase of 20 degrees or more is predicted. The reason for this error is the specification of the heat supply condition in the form of boundary conditions for the flow at the left end of the computational domain. In reality, when carrying out an experiment, the heat flux is set not at a point, but at a certain area on which the resistors are located. To take this effect into account in the model, instead of the boundary conditions for the flow on the left boundary, it was proposed to use the condition of distributed volumetric heat sources in the initial section of the computational domain with a length of $30 \mathrm{~mm}$. This made it possible to reduce the predicted overheating at the left end of the pipe (Fig. 5). The next refinement in the model is aimed at taking into account the nature of the temperature changes in the condensation zone.

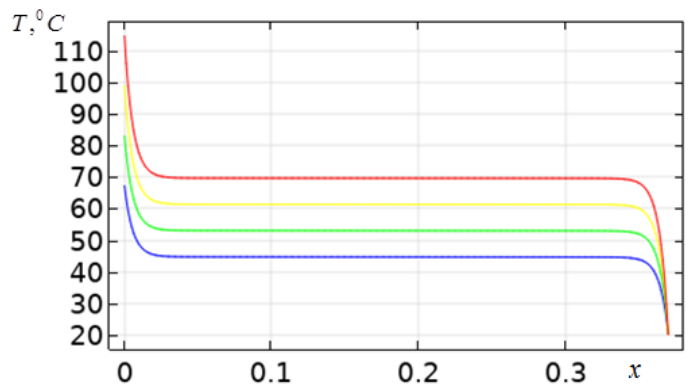

Fig. 4 Change in temperature along the length of the heat pipe, obtained within the framework of the model in a non-stationary setting, taking into account the dependence of the steam saturation temperature on the pressure in the parawire. Color designations are similar to Fig. 2.

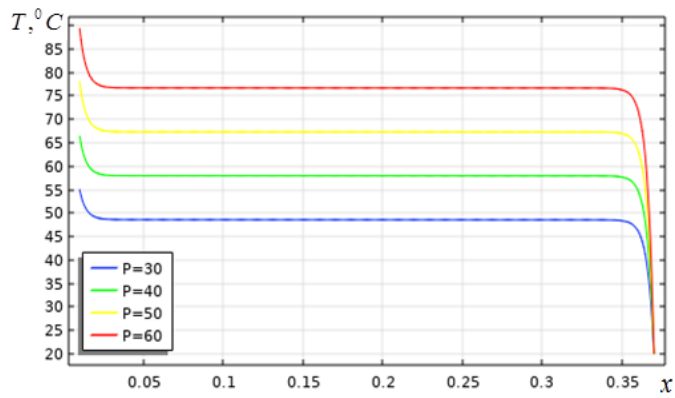

Fig. 5 The results of calculations within the framework of the model from the substituted boundary conditions along the flow at the left end to the condition of the presence of distributed volumetric sources in the initial section with a width of $30 \mathrm{~mm}$ - the temperature change along the length of the heat pipe. Color designations are similar to Fig. 2.

An explanation of this effect was obtained by introducing the assumption that the capillary limit in this zone is reached, that is, that the liquid pressure drop in the wick is exceeded the maximum capillary pressure that can be created by the used capillary-porous material. As can be seen from Fig. 4 in the area where the sources are located, a temperature increase of 20 degrees or more is predicted. In reality, when carrying out an experiment, the heat flux is set not at a point, but at a certain area on which the resistors are located. To take this effect into account in the model, instead of the boundary conditions for the flow on the left boundary, it was proposed to use the condition of distributed volumetric heat sources in the initial section of the computational domain with a length of 30 $\mathrm{mm}$. It means, in other words, that in this case, in the most remote cold zones of the TT, the coolant stops moving towards the condensation zone and the section where the capillary limit is reached turns out to be "turned off" from work. In the model, this was taken into account by introducing the assumption of a decrease in the heat transfer coefficient from the parawire to the wall of the TT (the mathematical formulation is given below). The results of the calculations refined in this way are shown in Figure 6. The corresponding pressure distribution along the length of the TT is shown in Figure 7. 


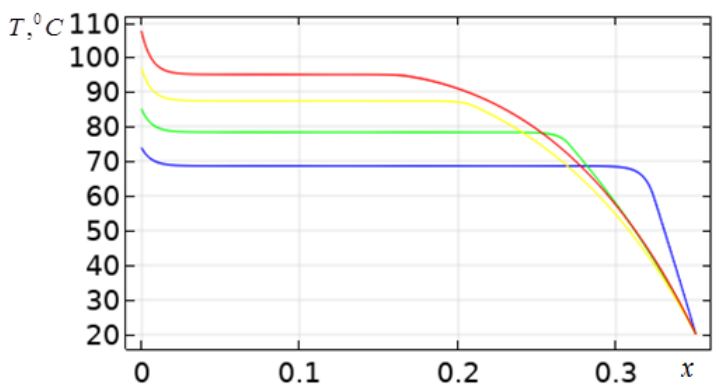

Fig. 6 Calculation results taking into account the achievement of the capillary limit in the condensation zone (the right end of the computational domain) - temperature change along the TT length. Color designations are similar to Fig. 2.

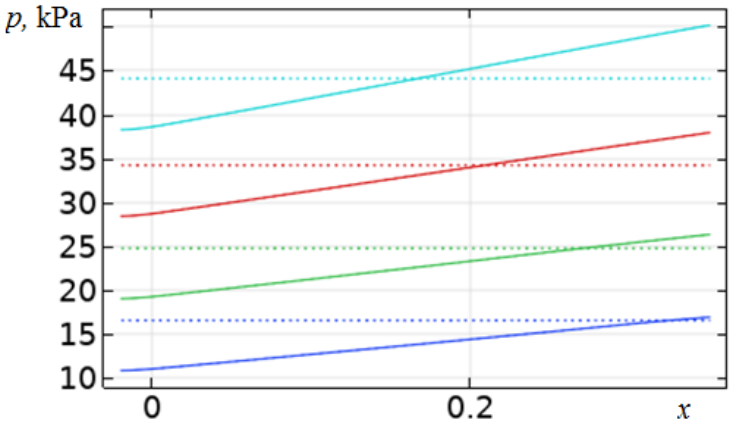

Fig. 7 Calculation results taking into account the achievement of the capillary limit in the condensation zone - pressure distribution in the capillary-porous material, $\mathrm{kPa}$. The dotted line shows the capillary limit. Color designations are similar to Fig. 2.

From Figures 6, 7 it can be seen that reaching the capillary limit (the point of intersection of solid lines and dashed lines in Fig. 7) leads in the proposed formulation of the model to a kink in the temperature graph, which qualitatively corresponds to the experiment. According to the results of the analysis, it turned out that the revealed effect can be explained by the dependence of the characteristics of the coolant on temperature. It is shown that the introduction of standard functions for the characteristics of the coolant (water) in the liquid and vapor state, as well as taking into account the capillary pressure on temperature, makes it possible to refine the resulting solution.

\section{CONCLUSION}

In this study, one-dimensional models of heat and mass transfer in heat pipes during cooling of active phased antenna arrays were developed, which can be used in processing the test results of flat heat pipes in order to determine their performance characteristics and identify the parameters required for modeling in a more complex setting.

Numerous calculations carried out made it possible to refine the mathematical model. In particular, a significant effect on the temperature distribution along the heat pipe is shown, taking into account the dependence of the steam saturation temperature on the pressure in the parawire.
It is shown that the introduction of standard functions for the characteristics of the coolant (water) in the liquid and vapor state, as well as taking into account the capillary pressure on temperature, makes it possible to refine the resulting solution.

\section{References}

[1] A. N. Astapov, E. L. Kuznetsova, L. N. Rabinskiy, "Operating capacity of anti-oxidizing coating in hypersonic flows of air plasma," Surface Review and Letters, 26(2), pp. 1850145, 2019.

[2] L. N. Rabinskiy, O. V. Tushavina, E. I. Starovoitov, "Study of thermal effects of electromagnetic radiation on the environment from space rocket activity," INCAS Bulletin, 12 (Special Issue), pp. 141-148, 2020.

[3] A. V. Babaytsev, A. A. Orekhov, L. N. Rabinskiy, "Properties and microstructure of AlSi10Mg samples obtained by selective laser melting," Nanoscience and Technology: An International Journal, 11(3), pp. 213222, 2020.

[4] O. V. Egorova, Y. K. Kyaw, "Solution of inverse nonstationary boundary value problems of diffraction of plane pressure wave on convex surfaces based on analytical solution," Journal of Applied Engineering Science, 18(4), pp. 676-680, 2020.

[5] M. Sha, Y. A. Utkin, O. V. Tushavina, P. F. Pronina, "Experimental studies of heat and mass transfer from tip models made of carbon-carbon composite material (cccm) under conditions of high-intensity thermal load," Periodico Tche Quimica, vol.17, i. 35, pp. 988-997, 2020.

[6] P. F. Pronina, O. V. Tushavina, E. I. Starovoitov, "Study of the radiation situation in moscow by investigating elastoplastic bodies in a neutron flux taking into account thermal effects," Periodico Tche Quimica, 17(35), pp. 753-764, 2020.

[7] A. A. Orekhov, Y. A. Utkin, P. F. Pronina, "Determination of deformation in mesh composite structure under the action of compressive loads," Periodico Tche Quimica, 17(35), pp. 599-608, 2020.

[8] A. V. Babaytsev, L. N. Rabinskiy, K. T. Aung, "Investigation of the contact zone of a cylindrical shell located between two parallel rigid plates with a gap," INCAS Bulletin, 12(Special Issue), pp. 43-52, 2020.

[9] V. G. Dmitriev, O. V. Egorova, E. I. Starovoitov, "Particularities of mathematical modeling of deformation processes for arched and panel designs of composites with large displacements and rotation angles," INCAS Bulletin, 12(Special Issue), pp. 53-66, 2020.

[10]O. A. Butusova, "Surface Modification of Titanium Dioxide Microparticles Under Ultrasonic Treatment," International Journal of Pharmaceutical Research, vol. 12, i. 4, pp. 2292-2296, 2020.

[11] O. A. Butusova, "Stabilization of Carbon Microparticles by High-Molecular Surfactants," International Journal of Pharmaceutical Research, vol. 12, Supplementary Issue 2, pp. 1147-1151, 2020.

[12] Yu. V. Ioni, A. Ethiraj, "New Tailor-Made Polymer Stabilizers for Aqueous Dispersions of Hydrophobic 
Carbon Nanoparticles," International Journal of Pharmaceutical Research, vol. 12, i. 4, pp. 3443-3446, 2020.

[13] Yu. V. Ioni, "Nanoparticles of noble metals on the surface of graphene flakes," Periodico Tche Quimica, vol. 17, no. 36, pp. 1199-1211, 2020.

[14] O. A. Butusova, "Vinyl Ether Copolymers as Stabilizers of Carbon Black Suspensions," International Journal of Pharmaceutical Research, vol. 12, Supplementary Issue 2, pp. 1152-1155, 2020.

[15] M. O. Kaptakov, "Catalytic Desulfuration of Oil Products under Ultrasonic Treatment," International Journal of Pharmaceutical Research, vol. 12, Supplementary Issue 2, pp. 1838-1843, 2020.

[16]B. A. Garibyan, "Enhancement of Mechanical Properties of Inorganic Glass under Ultrasonic Treatment," International Journal of Pharmaceutical Research, vol. 12, Supplementary Issue 2, pp. 1829-1832, 2020.

[17]M. O. Kaptakov, "Enhancement of Quality of Oil Products under Ultrasonic Treatment," International Journal of Pharmaceutical Research, vol. 12, Supplementary Issue 2, pp. 1851-1855, 2020.

[18]O. A. Butusova, "Adsorption Behaviour of Ethylhydroxyethyl Cellulose on the Surface of Microparticles of Titanium and Ferrous Oxides," International Journal of Pharmaceutical Research, vol. 12, Supplementary Issue 2, pp. 1156-1159, 2020.

[19]A. N. Tarasova, "Vibration-based Method for Mechanochemical Coating Metallic Surfaces," International Journal of Pharmaceutical Research, vol. 12, Supplementary Issue 2, pp. 1160-1168, 2020.

[20]B. A. Garibyan, "Mechanical Properties of Electroconductive Ceramics," International Journal of Pharmaceutical Research, vol. 12, Supplementary Issue 2, pp. 1825-1828, 2020.

[21]M. O. Kaptakov, "Effect of Ultrasonic Treatment on Stability of $\mathrm{TiO}_{2}$ Aqueous Dispersions in Presence of Water-Soluble Polymers," International Journal of Pharmaceutical Research, vol. 12, Supplementary Issue 2, pp. 1821-1824, 2020.

[22] Yu. V. Ioni, "Synthesis of Metal Oxide Nanoparticles and Formation of Nanostructured Layers on Surfaces under Ultrasonic Vibrations," International Journal of Pharmaceutical Research, vol. 12, i. 4, pp. 3432-3435, 2020.

[23]A. N. Tarasova, "Effect of Reagent Concentrations on Equilibria in Water-Soluble Complexes," International Journal of Pharmaceutical Research, vol. 12, Supplementary Issue 2, pp. 1169-1172, 2020.

[24]A. N. Tarasova, "Effect of Vibration on Physical Properties of Polymeric Latexes," International Journal of Pharmaceutical Research, vol. 12, Supplementary Issue 2, pp. 1173-1180, 2020.

[25] Yu. V. Ioni, A. Ethiraj, "Study of Microparticles Surface Modification by Electrokinetic Potential Measuring," International Journal of Pharmaceutical Research, vol. 12, i. 4 , pp. 3436-3439, 2020.
[26] Yu. V. Ioni, "Effect of Ultrasonic Treatment on Properties of Aqueous Dispersions of Inorganic and Organic Particles in Presence of Water-Soluble Polymers," International Journal of Pharmaceutical Research, vol. 12, i. 4, pp. 3440-3442, 2020.

[27] O. V. Egorova, E. I. Starovoitov, "Non-stationary diffraction problem of a plane oblique pressure wave on the shell in the form of a hyperbolic cylinder taking into account the dissipation effect," INCAS Bulletin, 12(Special Issue), pp. 67-77, 2020.

[28] O. V. Tushavina, "Coupled heat transfer between a viscous shock gasdynamic layer and a transversely streamlined anisotropic half-space," INCAS Bulletin, 12 (Special Issue), pp. 211-220, 2020.

[29] S. Vakhneev, E. Starovoitov, "Damping of circular composite viscoelastic plate vibration under neutron irradiation," Journal of Applied Engineering Science, 18(4), pp. 699-704, 2020.

[30] V. A. Pogodin, L. N. Rabinskii, S. A. Sitnikov, "3D Printing of Components for the Gas-Discharge Chamber of Electric Rocket Engines," Russian Engineering Research, vol. 39, no. 9, pp. 797-799, 2019.

[31] Y. K. Kyaw, E. L. Kuznetsova, A. V. Makarenko "Complex mathematical modelling of mechatronic modules of promising mobile objects," INCAS Bulletin, 12(Special Issue), pp. 91-98, 2020.

[32] L. E. Kuznetsova, V. G. Fedotenkov, "Dynamics of a spherical enclosure in a liquid during ultrasonic cavitation," Journal of Applied Engineering Science, 18(4), pp. $681-686,2020$.

[33] A. V. Makarenko, E. L. Kuznetsova, "Energy-Efficient Actuator for the Control System of Promising Vehicles," Russian Engineering Research, 39(9), pp. 776-779, 2020.

[34]E. L. Kuznetsova, A. V. Makarenko, "Mathematic simulation of energy-efficient power supply sources for mechatronic modules of promising mobile objects," Periodico Tche Quimica, 15(Special Issue 1), pp. 330338, 2018.

[35] Y. Li, A. M. Arutiunian, E. L. Kuznetsova, G. V. Fedotenkov, "Method for solving plane unsteady contact problems for rigid stamp and elastic half-space with a cavity of arbitrary geometry and location," INCAS Bulletin, 12(Special Issue), pp. 99-113, 2020.

[36] E. L. Kuznetsova, G. V. Fedotenkov, E. I. Starovoitov, "Methods of diagnostic of pipe mechanical damage using functional analysis, neural networks and method of finite elements," INCAS Bulletin, 12(Special Issue), pp. 79-90, 2020.

[37]Y. K. Kyaw, P. F. Pronina, P. O. Polyakov, "Mathematical modelling of the effect of heat fluxes from external sources on the surface of spacecraft," Journal of Applied Engineering Science, 18(4), pp. 732-736, 2020.

[38]L. N. Rabinskiy, S. A. Sitnikov, "Development of technologies for obtaining composite material based on silicone binder for its further use in space electric rocket engines," Periodico Tche Quimica, 15(Special Issue 1), pp. 390-395, 2018. 
[39] V. F. Formalev, S. A. Kolesnik, B. A. Garibyan, "Mathematical modeling of heat transfer in anisotropic plate with internal sinks," AIP Conference Proceedings, 2181, 020003, 2019.

[40] V. F. Formalev, S. A. Kolesnik, B. A. Garibyan, "Heat transfer with absorption in anisotropic thermal protection of high-temperature products," Herald of the Bauman Moscow State Technical University, Series Natural Sciences, (5), pp. 35-49, 2019.

[41]S. A. Kolesnik, N. A. Bulychev, "Numerical analytic method for solving the inverse coefficient problem of heat conduction in anisotropic half-space," Journal of Physics: Conference Series, 1474(1), 012024, 2020.

[42] V. F. Formalev, N. A. Bulychev, S. A. Kolesnik, M. A. Kazaryan, "Thermal state of the package of cooled gasdynamic microlasers," Proceedings of SPIE - The International Society for Optical Engineering, 11322, article number 113221B, 2019.

[43] V. F. Formalev, S. A. Kolesnik, B. A. Garibyan, "Analytical solution of the problem of conjugate heat transfer between a gasdynamic boundary layer and anisotropic strip," Herald of the Bauman Moscow State Technical University, Series Natural Sciences, 5(92), pp. 44-59, 2020.

[44] Y. Sun, S. A. Kolesnik, E. L. Kuznetsova, "Mathematical modeling of coupled heat transfer on cooled gas turbine blades," INCAS Bulletin, 12(Special Issue), pp. 193-200, 2020.

[45] I. Kurchatov, N. Bulychev, S. Kolesnik, E. Muravev, "Application of the direct matrix analysis method for calculating the parameters of the luminescence spectra of the iron ion in zinc sulfide crystals," AIP Conference Proceedings, 2181, 020015, 2019.

[46] B. A. Antufev, E. L. Kuznetsova, L. N. Rabinskiy, O. V. Tushavina, "Investigation of a complex stress-strain state of a cylindrical shell with a dynamically collapsing internal elastic base under the influence of temperature fields of various physical nature," Asia Life Sciences, (2), pp. 689-696, 2019.

[47] B. A. Antufev, E. L. Kuznetsova, L. N. Rabinskiy, O. V. Tushavina, "Complex stressed deformed state of a cylindrical shell with a dynamically destructive internal elastic base under the action of temperature fields of various physical nature," Asia Life Sciences, (2), pp. 775782, 2019

[48] L. N. Rabinskiy, O. V. Tushavina, "Problems of land reclamation and heat protection of biological objects against contamination by the aviation and rocket launch site," Journal of Environmental Management and Tourism, 10(5), pp. 967-973, 2019.

[49]A. N. Astapov, I. P. Lifanov, L. N. Rabinskiy, "Perspective Heat-Resistant Coating for Protection of $\mathrm{Cf} / \mathrm{SiC}$ Composites in Air Plasma Hypersonic Flow," High Temperature, 57(5), pp. 744-752, 2019.

[50] V. N. Dobryanskiy, L. N. Rabinskiy, O. V. Tushavina, "Validation of methodology for modeling effects of loss of stability in thin-walled parts manufactured using SLM technology," Periodico Tche Quimica, 16(33), pp. 650656, 2019.

[51] O. A. Butusova, "Chemical and Physical Properties of Magnetic Composite Materials," Studies in Systems, Decision and Control, to be published.

[52] O. A. Butusova, "Investigation of Adsorption Capacity of Magnetic Sorbents for Medical Application," Studies in Systems, Decision and Control, to be published.

[53]M. O. Kaptakov, "Enhancement of Physical and Mechanical Properties of Metal Surfaces Coated by Polymers," Studies in Systems, Decision and Control, to be published.

[54] B. A. Garibyan, "Determination of the Elastic Modulus of the Coating Using a Spherical Indenter," Studies in Systems, Decision and Control, to be published.

[55] M. O. Kaptakov, "Calculation of Physical and Mechanical Parameters of Metal Samples with Polymer Layers," Studies in Systems, Decision and Control, to be published.

[56] B. A. Garibyan, "Theoretical Estimations of Influence of Polymer Coatings on the Elastic Modulus and Ultimate Strength of Steel Samples," Studies in Systems, Decision and Control, to be published.

[57] M. O. Kaptakov, "Numerical and Analytical Study of Mechanical Characteristics of Nanocomposites Based on Carbon Additives," Studies in Systems, Decision and Control, to be published.

[58]M. O. Kaptakov, "Synthesis and Investigation of Composite Materials Reinforced with Carbon Wires," Studies in Systems, Decision and Control, to be published.

[59] V. F. Formalev, S. A. Kolesnik, E. L. Kuznetsova, "Analytical study on heat transfer in anisotropic space with thermal conductivity tensor components depending on temperature," Periodico Tche Quimica, 15(Special Issue 1), pp. 426-432, 2018.

[60] V. F. Formalev, S. A. Kolesnik, "Temperature-dependent anisotropic bodies thermal conductivity tensor components identification method," International Journal of Heat and Mass Transfer, 123, pp. 994-998, 2018.

[61] V. F. Formalev, S. A. Kolesnik, E. L. Kuznetsova, "Analytical solution-based study of the nonstationary thermal state of anisotropic composite materials," Composites: Mechanics, Computations, Applications, 9(3), pp. 223-237, 2018.

[62] V. F. Formalev, S. A. Kolesnik, "On Thermal Solitons during Wave Heat Transfer in Restricted Areas," High Temperature, 57(4), pp. 498-502, 2019.

[63] V. F. Formalev, S. A. Kolesnik, E. L. Kuznetsova, L. N. Rabinskiy, "Origination and propagation of temperature solitons with wave heat transfer in the bounded area during additive technological processes," Periodico Tche Quimica, 16(33), pp. 505-515, 2019.

[64] V. F. Formalev, S. A. Kolesnik, E. L. Kuznetsova, "Mathematical modeling of a new method of thermal protection based on the injection of special coolants," Periodico Tche Quimica, 16(32), pp. 598-607, 2019.

[65] O. A. Pashkov, "Influence of Polymer Coatings on the Mechanical Properties of Steel Samples in Tensile and 
Bending Tests," Studies in Systems, Decision and Control, to be published.

[66] O. A. Pashkov, "Investigation of the Effect of Steel Plate Size and Elevated Temperature on Critical Load in Stability Tests," Studies in Systems, Decision and Control, to be published.

[67] O. A. Pashkov, "Theoretical calculation of the thickness of interphase zones in the Al-Al2O3 composite," Studies in Systems, Decision and Control, to be published.

[68] O. A. Pashkov, "Experimental and Theoretical Study of Mechanical Properties of Matrix Composite Materials," Studies in Systems, Decision and Control, to be published.

[69] Y. Sun, O. V. Egorova, E. L. Kuznetsova, "Identification of the front angle of a plane acoustic oblique pressure wave on convex surfaces with the use of analytical solution," Journal of the Balkan Tribological Association, 27(2), pp. 189-197, 2021.

[70] V. F. Formalev, S. A. Kolesnik, "On Inverse Coefficient Heat-Conduction Problems on Reconstruction of Nonlinear Components of the Thermal-Conductivity Tensor of Anisotropic Bodies," Journal of Engineering Physics and Thermophysics, 90(6), pp. 1302-1309, 2017.

[71] V. F. Formalev, S. A. Kolesnik, "Analytical investigation of heat transfer in an anisotropic band with heat fluxes assigned at the boundaries," Journal of Engineering Physics and Thermophysics, 89(4), pp. 975-984, 2018.

[72] V. F. Formalev, E. M. Kartashov, S. A. Kolesnik, "Simulation of Nonequilibrium Heat Transfer in an Anisotropic Semispace Under the Action of a Point Heat Source," Journal of Engineering Physics and Thermophysics, 92(6), pp. 1537-1547, 2019.

[73]I. S. Kurchatov, N. A. Bulychev, S. A. Kolesnik "Obtaining Spectral Characteristics of Semiconductors of AIIBVI Type Alloyed with Iron Ions Using Direct Matrix Analysis," International Journal of Recent Technology and Engineering, vol. 8, i. 3, pp. 8328-8330, 2019.

[74] V. F. Formalev, S. A. Kolesnik, E. L. Kuznetsova, "Identification of new law for decomposition of bonding heat-shielding composite materials," Asia Life Sciences, (1), pp. 139-148, 2019.

[75]E. L. Kuznetsova, A. V. Makarenko, "Mathematical model of energy efficiency of mechatronic modules and power sources for prospective mobile objects," Periodico Tche Quimica, 16 (32), pp. 529-541, 2019.

[76] L. N. Rabinskiy, E. L. Kuznetsova, "Analytical and numerical study of heat and mass transfer in composite materials on the basis of the solution of a stefan-type problem," Periodico Tche Quimica, 15 (Special Issue 1), pp. 339-347, 2018.

[77]N. A. Bulychev, E. L. Kuznetsova, "Ultrasonic Application of Nanostructured Coatings on Metals," Russian Engineering Research, 39 (9), pp. 809-812, 2019.

[78]N. A. Bulychev, V. V. Bodryshev, L. N. Rabinskiy, "Analysis of geometric characteristics of two-phase polymer-solvent systems during the separation of solutions according to the intensity of the image of micrographs," Periodico Tche Quimica, 16(32), pp. 551$559,2019$.
[79]L. N. Rabinskii, O. V. Tushavina, "Composite Heat Shields in Intense Energy Fluxes with Diffusion," Russian Engineering Research, 39(9), pp. 800-803, 2019.

[80] L. N. Rabinskiy, O. V. Tushavina, "Investigation of the influence of thermal and climate effects on the performance of tiled thermal protection of spacecraft," Periodico Tche Quimica, 16(33), pp. 657-667, 2019.

[81] V. V. Bodryshev, L. N. Rabinskiy, L. G. Nartova, N. P. Korzhov, "Geometry analysis of supersonic flow around two axially symmetrical bodies using the digital image processing method," Periódico Tchê Química, vol. 16, no. 33, pp. 541-548, 2019.

[82] N. A. Bulychev, M. A. Kazaryan, A. I. Erokhin, A/ S/ Averyushkin, L. N. Rabinskii, V. V. Bodryshev, B. A. Garibyan, "Analysis of the Structure of the Adsorbed Polymer Layers on the Surfaces of Russian Metallurgy (Metally)," vol. 2019, no. 13, pp. 1319-1325.

\section{Contribution of Individual Authors to the Creation of a Scientific Article (Ghostwriting Policy)}

S. Radaev carried out the mathematical modelling and calculations.

\section{Creative Commons Attribution License 4.0 (Attribution 4.0 International, CC BY 4.0)}

This article is published under the terms of the Creative Commons Attribution License 4.0 https://creativecommons.org/licenses/by/4.0/deed.en_US 